ALPHA N² 28 Julio 2009 (29-44)

ISSN 0716-4254

http://alpha.ulagos.cl

\title{
COMUNICACIÓN INTERCULTURAL Y ARTE MAPUCHE ACTUAL ${ }^{1}$
}

Intercultural communication and contemporary mapuche art

\section{Mabel García Barrera*}

\section{Resumen}

Las actuales producciones del arte mapuche (poesía, cuento, plástica, escultura, teatro, dibujo, entre otras) si bien refieren a una pluralidad discursiva se articulan como un proyecto cultural bajo características transversales, que se encuentran conformando un sistema estético-cultural propio y diferenciado que actúa como una propuesta contrahegemónica y contracultural en un contexto intercultural asimétrico. Lo anterior supone evaluar cómo estos proyectos artísticos implementan mecanismos discursivos y comunicativos de acuerdo a una función de retradicionalización y visibilización cultural.

Palabras clave: Pueblo mapuche, arte mapuche, comunicación, estudios interculturales, retradicionalización.

\section{Abstract}

Contemporary literary and non-literary mapuche production in art such as poetry, short stories, drawings and play performances among others, refer to a variety of discourses joined around a cultural project under transverse common characteristics. These facts allow us to think about a cultural aesthetic system of their own but different on the basis of their background which works as a proposal opposing the hegemonic asymmetrical intercultural context. Our aim is to evaluate how these artistic projects put into operation communicative and discursive elements according to cultural tradition and visibility.

Key words: Mapuche people, mapuche art, communication, intercultural (studies), tradition, retraditionalization.

\footnotetext{
${ }^{1}$ Artículo derivado del Proyecto DIUFRO D107-0005 "La dinámica estético-cultural del actual discurso artístico mapuche: aproximación a la relación entre poesía y visualidad”, que dirige la autora y en el cual actúan como co-investigadores Hugo Carrasco Muñoz y Sonia Betancour Sánchez. Las imágenes reproducidas aquí en blanco y negro pueden ser apreciados a color en la versión en línea. http://www.scielo.cl/scielo.php?script=sci_serial\&1ng=es\&pid=0718-2201.
} 


\section{Mabel García Barrera}

\section{CONSIDERACIONES INICIALES}

Damos cuenta, aquí, de los resultados parciales de un proyecto de investigación formal en cuya hipótesis se establece la existencia de elementos transversales entre las diferentes producciones artísticas que realiza actualmente el pueblo mapuche, de donde se sugiere que estos discursos artísticos se orientan a la formación de un sistema estético-cultural propio y diferenciado (Cfr. García, M. 2007). Esta premisa surge de una lectura específica que relaciona este proceso artístico con la transformación histórico-política y cultural del pueblo mapuche, vinculada a los acontecimientos de orden hegemónico y de dominación política que le han afectado de diverso modo desde el inicio de la conquista española y que se han perpetuado bajo distintos mecanismos en la posterior constitución del Estado nación-chileno.

En este transcurso, desde su origen, las expresiones de arte mapuche se caracterizan por su impronta intercultural. Sin embargo, desde la producción inicial de las chaquiras, la cerámica y los textiles en el período pre-hispánico, los adornos y las joyas en plata en el período colonial, el cambio más significativo se manifiesta a fines del siglo XX cuando irrumpen diversos proyectos artísticos - poéticos, narrativos, visuales, teatrales, musicales, entre otros- expresados en heterogéneos soportes que definen un arte vinculado directamente con la resistencia y reivindicación cultural, situación que, de alguna manera, permite señalar un antes y un después en los procesos de adopción e innovación cultural que realiza el pueblo mapuche en el campo del arte y que permiten diferenciar el llamado arte tradicional del denominado arte actual.

Para sintetizar de manera general un proceso artístico-cultural tan complejo, destacaré tres problemas que se refieren a su estado actual, los cuales se encuentran asociados al campo de la estética, la producción artística y su situación de enunciación.

Desde una mirada retrospectiva, el primero y del cual escasamente se sabe algo alude a entender cuáles son las características constitutivas y los principios básicos del canon estético de la cultura tradicional mapuche, principal referente para estudiar los posibles cambios en la conservación, transformación y/o innovación de las expresiones artísticas de este pueblo a lo largo del contacto cultural, ya sea con la cultura incaica en el período precolombino, la española posteriormente, la chilena después y, actualmente, con la denominada sociedad global.

El segundo problema surge desde el momento cuando se establecen las actuales producciones, lo que nos devuelve inevitablemente al primer problema que es entender hoy cuál es el canon estético que sostiene el sistema en formación y en qué medida se encuentra anclado en los criterios y 
características del canon tradicional ancestral, dado que estos proyectos fortalecen cada vez más la función de retradicionalización que tendrían las obras como espacios de diálogo intracultural y, simultáneamente, obras de resistencia y de reivindicación cultural respecto del diálogo con la cultura hegemónica.

Este último proceso añade una interrogante adicional como es saber qué elementos y/o procesos colaboran en la constitución de este sistema, cuya respuesta deviene evidentemente, en parte, del ámbito contextual en el cual la creciente desarticulación del sistema hegemónico tradicional, que se acomoda o se transforma bajo los cambios políticos y económicos de la globalización, genera un nuevo escenario para la producción artística mapuche que se establece estratégicamente como un sistema contra-hegemónico y contracultural.

En este sentido, no sólo el origen sino las características y la dirección que adquiere y explican este sistema estético-cultural, se vinculan a una posición que acentúa la diferencia étnico-cultural que busca transformar o, a lo menos, desvincularse de las formas de control y mecanismos que implementa el sistema hegemónico vigente. Lo anterior se debe a la larga experiencia negativa que se ha tenido de vivenciar un sistema que regula los "significados y valores" del conjunto social y que se articula como "una cultura" de dominación y subordinación que afecta no sólo la mirada sobre sí, sino de los unos a los otros en las relaciones personales directas, la comprensión del mundo natural y el cómo verse dentro de él, la utilización de los recursos físicos y materiales en relación con lo que un tipo de sociedad explícita como “ocio”, “entretenimiento” y “arte” (Williams, 1980).

Desde este punto de vista, la incidencia que tiene este tipo de contexto para la actual producción discursiva del pueblo mapuche ha delimitado ciertas posiciones y comportamientos de respuesta a lo hegemónico como práctica enunciativa, de la cual forman parte los discursos políticos, públicos y artísticos orientados hacia la sociedad global. Estos dan cuenta de un complejo proceso comunicativo de carácter transcultural que desborda los límites de las formas comunicativas tradicionales - eminentemente oralespara anclarse en la frontera de las formaciones discursivas occidentales, a la vez que asumen la condición del espacio discursivo en que se generan —el del contacto cultural- donde se cruzan y/o afianzan elementos y mecanismos de la comunicación intercultural.

En la irrupción de este lugar intermedio se presentan los actuales discursos artísticos mapuches, como el ámbito donde prevalece la "práctica estética” con "su potencial legibilidad pública y colectiva” (Büchloh, 2000) constituyéndose en un espacio de visibilización de las problemáticas culturales y/o interculturales, donde por una parte se construye un meta-relato 


\section{Mabel García Barrera}

hacia la cultura propia y ajena que reflexiona y comunica una visión particular y de conjunto sobre el ethos cultural y, por otra, se articulan códigos y estrategias que devienen de los recursos del discurso artístico y de la comunicación occidental.

También, en este espacio de hibridación discursiva y comunicativa se cuestionan y debaten enfoques, conceptos y procesos tan significativos como las nuevas formas y funciones que tiene la comunicación en las sociedades pluriculturales, cuyo ejemplo se encuentra en la creciente desconfianza que se tiene en los mecanismos que implementa el gobierno para la actual relación intercultural, por cuanto, para una parte de los actores involucrados - los grupos carentes del control político y económico - el mismo supuesto de "interculturalidad" no les es fiable y, en este sentido, desde las culturas originarias se propone constantemente la reconstrucción o reestructuración de ciertos constructos y de descolonización, incluso, del mismo concepto y con ello de las prácticas etnocéntricas que introduce, en la medida que sólo han legitimado la relación asimétrica.

Así, se observa que las políticas de orientación intercultural han servido -más que a generar una práctica democrática y equitativa entre las culturas - a propiciar que los miembros de las culturas originarias realicen un proceso de recuperación de su cultura ancestral y de las prácticas tradicionales, donde se apuesta por la reelaboración y/o descubrimiento de una identidad cultural propia que se reafirma y no a establecer cambios estructurales como el ser reconocidos sujetos de derecho.

Para los creadores mapuches, ubicar estratégicamente el actual espacio de contacto cultural como el lugar de la enunciación, ha sido un proceso de aprendizaje y de adecuación constante donde se lucha por establecer criterios estéticos propios y, con ello, visibilizar la diferencia cultural. Con este propósito, los creadores mapuches generan una obra orientada hacia un tipo específico de comunicación: la comunicación intercultural, en tanto lugar donde se vivencian, resignifican y direccionan epistémica, estética y éticamente los referentes culturales de unos y otros.

La complejidad de esta relación cultural radica principalmente en la distancia que tienen los paradigmas culturales en contacto al corresponder a matrices culturales opuestas donde la lengua, la religión, la organización social y política, es decir, el conjunto de prácticas culturales refieren a percepciones que distancian los modos de organización cognitiva sobre el mundo, la naturaleza, las relaciones personales y espirituales. Para entender de qué hablamos cuando nos referimos a este proceso de comunicación intercultural, aludo a algunos criterios que ha propuesto Rodrigo Alsina (1999) para el logro de una comunicación intercultural eficaz, entre los que se encuentran el establecimiento de una lengua común para interaccionar, una 
nueva competencia comunicativa y un cierto conocimiento de la otra cultura, junto con ello una toma de conciencia de la propia cultura y el desarrollo de la capacidad de metacomunicarse: "Es decir, tener la capacidad de decir lo que se pretende decir cuando se dice algo" (1999:7). Por otra parte, el desarrollo de la empatía para la mejor comprensión del otro y a través de las emociones aumentar esta comprensión, la adecuación contextual y finalmente entender que las relaciones sociales son relaciones de poder y por lo tanto en la comunicación también se manifiestan estas relaciones.

La reflexión que cabe aquí respecto de estos criterios es que algunos o muy pocos forman parte de la práctica habitual de los miembros de la cultura dominante, pues, el mayor esfuerzo ha devenido de los miembros de la cultura mapuche por el mismo proceso de homogeneización cultural que les ha obligado a transitar desde la oralidad a la escritura y de la comunicación en mapuzungun a comunicarse en la lengua castellana; tener una religión, la católica en principio, y hoy por hoy, en general, la denominada cristiana; una institucionalidad política y legal, regida por la Constitución chilena; entre otros.

En este intersticio del contacto cultural, el artista construye los textos desde una práctica contracultural que polemiza con el discurso institucionalizado, hegemónico y dominante, y que afecta a la producción artística en dos esferas que le son propias para sus propósitos: la estética y la comunicativa. Mientras en la primera lucha por desplazar los criterios y cánones occidentales en los que ha construido inicialmente las actuales producciones artísticas y busca reemplazarlos (de hecho y simbólicamente) por los criterios y cánones de la cultura tradicional (García, 2008) en el ámbito comunicativo de estos textos se aspira a instalar un nuevo modelo de contacto e interacción que se defina por una práctica comunicativa simétrica.

Raymond Williams (1980) ha explicado este proceso de negociación cultural como la ocurrencia de fuerzas culturales subordinadas, residuales, emergentes, alternativas y oposicionales en coexistencia con las dominantes, las que establecen entre sí distintas relaciones de incorporación, negociación y resistencia; vinculadas - desde otro punto de vista - con grupos sociales o culturales y generacionales que confrontan estructuras de sensibilidad distintas. Esta reflexión bien puede ser aplicada a luz de la generación de artistas mapuches que, por circunstancias históricas específicas de inicios de la década de los noventa - la conmemoración de los quinientos años de la Conquista de América, el pacto de la coalición política de la Concertación con los representantes de los Pueblos Originarios por la vuelta a la democracia, y su posterior concreción en la actual Ley indígena № 19.253 del año 1993éstos se relacionan conscientes del giro histórico-político y cultural que se 


\section{Mabel García Barrera}

produce para liderar mediante acciones de arte este proceso de recuperación y resistencia cultural (García, 2006).

\section{EL SISTEMA EN PROCESO DE CONSTITUCIÓN: INTENCIONES VERSUS AMBIGÜEDADES}

Si bien la década de los noventa nos sorprende con una heterogénea producción de obras, principalmente publicación de textos poéticos y la exposición y difusión de textos visuales y audiovisuales, la década presente nos alerta sobre un rápido cambio en el sistema de articulación y difusión de éstas. Así Viaje al Osario de Juan Paulo Huirimilla (2005) Hierba Agua de Leonel Lienlaf (2006) publicado en formato digital y distribuido por red; Veinte poemas alados de los bosques nativos de Chile de Lorenzo Aillapán (2005), formato en papel y digitalizado en audio; Sembrando vida. Wallmapu entre imágenes y poesía (2007); Voz de mujer. Poesía de mujeres mapuches para todos (2008), ambos del Colectivo We Newen, publicados y distribuidos digitalmente desde EEUU; la Primera mención al mérito artístico en la Bienal Intercontinental de Arte indígena para artistas visuales (2008) otorgada a Lorena Lemunguier y Daniel Huencho en Ecuador y que nos llega a través de la difusión en el espacio digital; la difusión de música por redes virtuales como la del Kolectivo We Newen Mapuche $(2006,2007,2008)$ y del grupo Wechekeche Trawun (2008), vinculada con la contingencia política; las premiaciones obtenidas por la cineasta Jeannette Paillán - Primer Premio Festival de las Naciones (Canadá, 1996) Premio Especial a la mejor investigación histórica (Argentina, 2003) Premio ciudad de Córdoba (España, 2008) — son algunos ejemplos del dinamismo que actualmente adquiere el arte mapuche y que nos aproxima a un nuevo escenario que se asocia a las problemáticas del arte en el ámbito que inscribe la globalización y la internacionalización de la cultura.

Algunas de estas problemáticas, ya referidas por Adorno y Horkeimer (1987) y Debord (1967) a inicios del siglo XX cuando establecían la negación de la autonomía de la obra de arte al colocarse éstas con orgullo entre los bienes de consumo, mueve a reflexionar sobre los diversos objetivos de este posicionamiento: resistencia cultural, factores de sustentabilidad económica, reconocimiento social, entre otros. Este nuevo posicionamiento se encontraría asentado sobre una de las características principales que se le ha reconocido a este pueblo en la conservación de su cultura: su dinamismo cultural, que le ha permitido reelaborar — aún en situaciones de conflicto extremo- sus estructuras esenciales, proceso en el cual se puede explicar el origen de los criterios y mecanismos estéticos, discursivos y comunicativos que ha implementado en estas últimas décadas para dar continuidad a su expresión artística. 
La emergencia de la nueva propuesta, sobre todo a nivel del proceso comunicativo, tensiona al texto artístico en varios niveles al inscribir en el espacio textual factores que corresponden a un modelo comunicativo tradicional (asimétrico, unidireccional, estático) con aquellos pertenecientes a un modelo más dialógico y democrático (simétrico, bidireccional, dinámico) suscitándose una serie de perspectivas, significados y sentidos encontrados.

Desde este punto de vista, una de las crisis de este sistema textual se encuentra en la ambigüedad formal que suscita el rol atribuido al receptor o al espectador (¿Quién?) y a la posibilidad de hacer contacto (¿Con quién?) provocada por un emisor textual que interpela continuamente al "otro" a través de la imagen cristalizada que ha fijado en el tiempo. Esta imagen cristalizada corresponde la mayor parte de las veces al estereotipo del dominador (García, 2006) mientras simultáneamente adopta una actitud dialógica hacia aquél sustentada en la suposición de "escucha" y "entendimiento" para lo que centra el discurso en diversas proposiciones: explicativas, sobre el ser cultural tradicional; descriptivas, de los procesos culturales e interculturales; argumentativas, en pro de la reelaboración de los acontecimientos históricos y, evaluativas, de las acciones procedimentales tanto de la cultura propia como de la ajena. Este proceso textual direccionado hacia el "otro" de manera persistente, bien puede relacionarse con la reafirmación de una identidad étnico-cultural colectiva lesionada por la intervención histórica donde se busca reforzar la imagen de sí a partir de la pareja especular: ya sea confrontando al estereotipo hegemónico, o a través de un nuevo tipo demarcado en lo democrático o, a lo menos, próximo a la actual etapa de las relaciones culturales.

Otros factores críticos que socavan este énfasis por lo dialógico - en esta aspiración por tomar "contacto" - es la incrustación, cada vez más permanente y casi solipsista, de lo propio como centro del despliegue semántico, despliegue que para su manifestación se funde paradójicamente con códigos y lenguajes devenidos de la cultura propia y ajena, incidiendo fuertemente en los mecanismos y estrategias de traducción cultural.

En esta tensión entre el deseo y el logro, se establece la circularidad de un proyecto comunicativo siempre inconcluso aunque discursivamente completo, demostrando una ambivalencia que nos pone de lleno frente a los procesos de resistencia cultural al propiciarse el texto como la formación de un lugar común donde debatir y contra-argumentar las estructuras hegemónicas, dar cuenta de sí en la diferencia y referir al "otro" sus necesidades. Surge de lo anterior, en el espacio textual, la revisión histórica y la implementación de una serie de mecanismos que se vinculan simultáneamente con la territorialización simbólica. 


\section{Mabel García Barrera}

En esta dinámica, la orientación dialógica se introduce, implícita o explícitamente, como un aspecto o como la totalidad de la estrategia textual o como un factor contextual que orienta su sentido en la situación de producción/recepción textual, estableciendo la hibridación como una de sus características específicas (Carrasco, 1993).

Me he referido en trabajos anteriores a las características que adquiere la dimensión dialógica en los textos poéticos y narrativos (García, 2005b) en cuya primera etapa, habitualmente, se busca calificar de alguna manera el proceso histórico a través de una secuencia discursiva que reconstituye una imagen cristalizada de los acontecimientos y de los roles antagónicos que han tenidos “unos” y “otros”, mientras la producción de esta década nos entrega un texto cada vez más cifrado, donde las metáforas del encuentro cultural y sus tensiones históricas o tensiones epistemológicas, quedan sujetas a la interpretación de la competencia contextual.

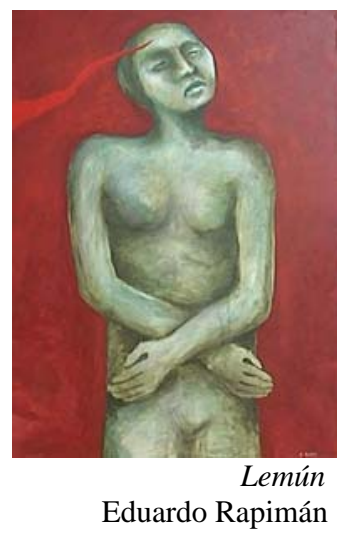

Así también en la plástica, como destacaré preferentemente en este trabajo, el mecanismo dialógico surge enmascarado dado que ubica habitualmente el tema del conflicto intercultural e interétnico a nivel simbólico, demandando al espectador competencias tanto de los elementos que aluden a la dinámica de la cultura tradicional como a la dinámica intercultural vigente.

Uno de estos ejemplos es Lemún de Eduardo Rapimán (2005), obra escultórica que simboliza, a varios niveles, este proceso dialógico. Mientras, por una parte, se busca expresar el dolor por la muerte de este joven mapuche, baleado durante una protesta por policías chilenos el año 2002, por otra, el trabajo plástico se centra en insinuar una lectura cultural tradicional de la representación al proponer la figura central como una obra escultórica, homologando en los trazos el tallado en madera que da forma al "che mamüll” (gente de madera), escultura propia del ritual de los muertos y que representa 
el espíritu de los antepasados en tanto figura protectora. Así, "el artista busca reconstruir históricamente lo no re-construible en la contingencia humana, capturando la esencia espiritual” (García, 2005:206) que define un modo de presencia del "ser". Con ello enfatiza el carácter estático de la figura, para lo cual ocupa una perspectiva bidimensional que se conjuga con lo escultórico tradicional, pues, fija en un mismo espacio y, al mismo tiempo, lo inamovible y lo trascendente. En el trasfondo cultural, la lectura de la obra se orienta a enfatizar la etapa de transición del "Am" (espíritu) desde el "nag mapu" (tierra visible) al "wenu mapu” (la tierra invisible).

Por otra parte, la orientación epistemológica que adquiere este arte remite al sentido especular que manifiesta esta producción artística. En ella, la representación contiene y se convierte en un metadiscurso que autorreflexiona desde la condición del sujeto —y desde la cultura subordinada - los argumentos implicados en el transcurso de la relación intercultural asimétrica (el atropello histórico, el estado actual de estas relaciones) y la propia condición histórica y cultural del pueblo mapuche y del artista en estas circunstancias. Así surge una propuesta que argumenta su discurso hacia dos direcciones: por una parte, anclada en el conflicto histórico y, por otra, centrada en la recuperación de los lenguajes y categorías culturales propias. Desde este punto de vista, se reconstruye la narración del conflicto hegemónico, se muestran los estereotipos, se reelabora la dimensión histórica como re-escritura, se establece la denuncia y se muestra, también, lo propio de la cultura tradicional como reescritura del conflicto al señalar metafórica-mente la presencia de un "aún estamos aquí”.

Este proceso se puede entender en el sentido que refiere Bhabha: "Ya no estamos enfrentados con un problema ontológico del ser sino con la estrategia discursiva del momento de la interrogación...” (2002:71).

Así, la función que orienta los procedimientos discursivos en esta dimensión es hacia la metacognición y, consecutivamente, hacia la recomposición cultural. Surgen aquí las proposiciones de un discurso argumentativo articulado por diversos íconos que se cruzan superponiéndose y que devenidos de las culturas en contacto, potencian una iconografía compleja que introduce la lectura en el relato histórico.

En este sentido, Una historia de terror (2006), de Eduardo Rapimán, orienta, por una parte, hacia una lectura pluricodificada que busca destacar el atropello cultural y la violentación hegemónica y, por otra, tiende a descalificar los parámetros y ópticas con que Occidente ha sesgado históricamente la imagen del pueblo mapuche. Rapimán propone una "instalación” que, siguiendo el concepto escenográfico de lo espectacular, deviene en un montaje heterogéneo cuyo soporte principal son las fotografías y los íconos del sistema de intercambio económico de la cultura occidental globalizada; 


\section{Mabel García Barrera}

íconos que se representan a través del sistema de barras y de monedas donde se inscribe el rostro de una mujer mapuche.

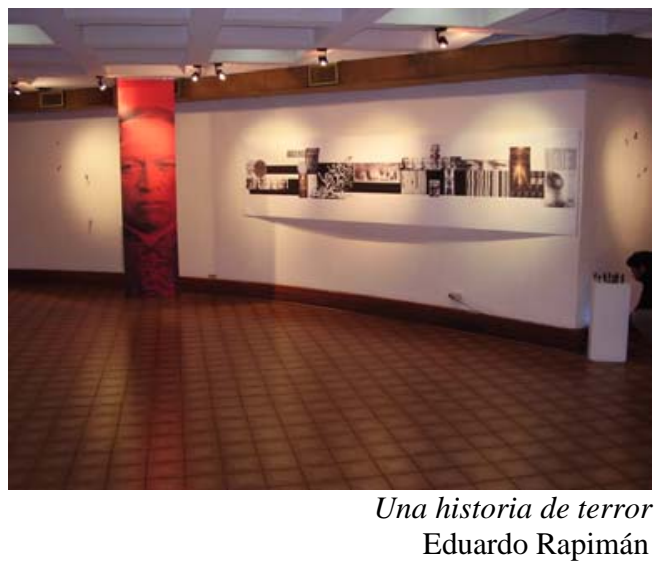

Mediado con lo anterior, se desplaza la lectura cultural tradicional: los códigos de barra se mezclan con la urdimbre del textil tradicional, mientras las fotos intervenidas digitalmente corresponden a las que el fotógrafo Gustavo Milet difundió como imagen estereotipada del mapuche ( $C f \mathrm{r}$. Azócar, A. 2005). Se suman a lo anterior, las radiografías como un modo de aludir a la carga visual del estereotipo que construyó occidente del "otro".

En el arte visual, normalmente, se busca restablecer la separación sujeto-objeto. Concordante con la epistemología cultural tradicional, Rapimán busca dar con el procedimiento contrario a la perspectiva occidental; releva el concepto de reificación que hace ésta sobre la cultura mapuche, proponiendo o haciendo visible la mercantilización como un discurso que debe ser marcado, una y otra vez, para provocar y convocar la diferencia cultural.

En esta instalación (pastiche) se utilizan todos los medios técnicos del diseño para obtener un texto orientado a la denuncia y donde el énfasis de lo especular se vacía en la mirada - esa que ha realizado Occidente- como punto de distorsión de lo visual y del imaginario construido. Esta inflexión crítica es la que identifica a esta obra como representativa de lecturas que buscan desnudar la mirada colonialista, ya sea por una repetición constante 0 por la omisión de ciertos significantes ya legitimados.

Sin embargo, ya sea en la poesía o en la visualidad - a través de la plástica, escultura o el dibujo - desde el punto de vista de las estrategias textuales se establece el tratamiento de la perspectiva o focalización homologando el carácter fotográfico sobre el acontecimiento; así se busca representar la totalidad del sistema cultural a partir del carácter metonímico de 
la obra. Coherentemente con lo anterior, también se busca una expresión centrada en los códigos propios, dinamizando en el espacio textual por una parte, una lectura de apropiación e innovación de lenguajes, cánones y textos ajenos y, por otra, de retradicionalización y resignificación de los cánones propios, observados éstos principalmente a través de la intervención del pewma (sueño), el rito, el mito y/o el machi ül (canto de machi).

Un ejemplo de esta constante en la poesía (García, 2006;2008) es articular el significado y el sentido de la obra a través de abrir el poemario con diversos discursos rituales tradicionales; estrategia empleada por Bernardo Colipán en Arco de Interrogaciones (2005), por César Millahueique en Oratorio al Señor de Pucatrihue (2004) y por David Aniñir en Mapurbe (2006). En estos textos se alude sucesivamente a la oración del "Nguillatun" (oración ritual a los seres superiores) a los "pewma" (sueños) y se resignifica el discurso del "Yeyipun”, como un conjuro para compensar el estado de precariedad y de desequilibrio del ser mapuche en la situación de desarraigo. En el caso de la plástica, esta orientación se encuentra marcada por símbolos y códigos altamente cifrados, donde sobre todo se apuesta por la creación de códigos que expresen lo que la iconografía tradicional no contemplaba.

En tal sentido, Rapimán alude a su trabajo plástico como "una serie de elementos (que) convergen en mi obra a modo de formas, volúmenes, colores y texturas que unidas a la experiencia espiritual del conocimiento mapuche me sumerge en el relato y testimonio de una identidad cultural mestiza y conflictuada. La presencia de estos signos, máscaras, personajes antropomorfos y animales responde a la comunión con un mundo ancestral poblado de seres fabulosos, los que revelan su mensaje a partir de ritos y ceremonias. Por tal motivo busco la integración de este mundo ancestral en un lenguaje del presente, así nace la composición enérgica de estas realidades en mi pintura” (2003).

En esta misma orientación, Christian Collipal (escultor y también músico) ha realizado desde sus proyectos iniciales una exploración por los lenguajes tradicionales de las culturas originarias del norte de Europa e indoamericanas, así como de su propia cultura con el fin de proponer un lenguaje propio que dé cuenta de la complejidad del sistema cultural mapuche tradicional, sobre todo, de la expresión de aquellos procesos que tienen relación con las fuerzas o energías que conectan las dimensiones visibles e intangibles del cosmos cultural.

En El Señor de los Pájaros II, Collipal codifica rigurosamente el ritual de nguillatun a través de uno de sus elementos centrales, como es la escala ritual ascendente de números cifrados en proporción geométrica, que representa lo infinito y trascendente, y que se homologan en las circunferencias de 


\section{Mabel García Barrera}

color rojo, mientras que por otra parte se muestran —a través de las circunferencias de color blanco- las lunas del año mapuche.

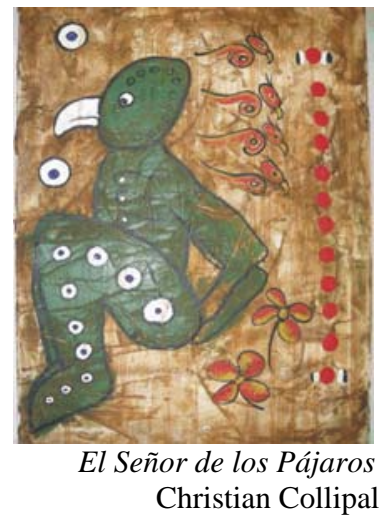

El Señor de los Pájaros (2002) corresponde a un proyecto de tres obras que pone en el centro del proceso identitario del artista el modo cómo éste asume el rescate de los significados ancestrales y también territoriales y normativos de la cultura, en tanto muestra y demuestra ante sí y ante los miembros de la cultura la competencia del saber tradicional, ubicándolo hacia adentro o hacia afuera del dominio cultural, situación no menos compleja para legitimar su pertenencia a la cultura.

Así, la dimensión estética de la obra de arte y su función de visibilización de las problemáticas interculturales, se convierte en un espacio crítico para el proceso de la creación artística. Se trata de resolver una propuesta con identidad propia y diferenciada en medio de la tensión que provoca a la obra mediar su constitución entre cánones estéticos propios -resignificados y/o transformados de la cultura tradicional - y aquellos acogidos como préstamo cultural, sobre todo, devenidos de la cultura occidental.

En este sentido, los mecanismos de innovación/conservación y apropiación/transformación de los cánones discursivos y la búsqueda de nuevos lenguajes que traduzcan en diferentes códigos aquello que se busca representar, conduce hacia un sistema que atraviesa una etapa fuertemente experimental, situación a la que se suma, además, la apuesta permanente por la integración de los principios culturales y los referentes histórico-políticos. Esta dinámica compleja anexa a este nuevo sistema artístico, normalmente, un disímil y heterogéneo conjunto de obras y proyectos atravesados por una perspectiva personal del imaginario cultural tradicional que se pretende recuperar -lo que tiene su origen en los procesos de mestizaje y/o transculturación- y que opera concretamente en tanto que cada artista 
vivencie de una manera distinta su identidad étnico-cultural y, con ello, el modo de establecer todas estas relaciones en la representación.

Sin embargo, el centro de los proyectos artísticos pasa por recuperar un sistema de estético vinculado a una expresión de lo armónico, como equilibrio de los opuestos, y cuya complejidad radica en que entre los puntos equidistantes se encuentra un universo formado por planos diferenciados e intercomunicados, compuesto por múltiples elementos, niveles y subniveles, en los cuales se movilizan energías - seres y fuerzas - según funciones y roles, todo ello bajo la concepción dinámica de una cosmovisión sacralizada, con códigos especializados y, muchos de ellos, de conocimiento restringido.

En lo visual, la forma de representación tradicional ante este nivel de complejidad ha sido una expresión simbólica, estática y plana. En lo narrativo es fuertemente simbólica y condensada en sus significados y significantes, opuesta a la práctica cultural ritual que busca dar cuenta de esta complejidad.

Desde este punto de vista, entender qué es la dimensión estética de la obra es distinguir los criterios de lo bello en la dinámica cultural, donde se conjuga lo religioso con lo pragmático, lo expresivo con lo funcional lo que, también, ayuda a explicar la orientación práctica de ésta, de proyectos artísticos que se articulan formando un sistema en franca progresión hacia consolidar su propia autonomía y en relación directa con la resistencia y reivindicación cultural.

\section{ALGUNAS CONCLUSIONES PARCIALES}

Este sistema en desarrollo, como proyecto, transparenta mediante el arte una forma de comprensión de sí mismo como pueblo y cultura y su sentido en una circunstancia histórica, traduciendo su vuelta hacia el pasado como el tiempo propio de la cultura tradicional, lo que da sentido a la recuperación de la matriz cultural ancestral, deshaciendo conflictuadamente la supremacía de una episteme impuesta para recuperar la propia.

Desde este punto de vista, la obra artística adquiere su articulación a partir del criterio de la diferencia cultural, criterio que permite el repliegue de la representación hacia sí como cultura originaria desde la cual se posiciona para establecer los gestos contrahegemónicos y contraculturales. Desde el punto de vista de su función, este sistema se articula como territorialización simbólica del ethos cultural, medio de visibilización de las problemáticas interculturales y mecanismo de reafirmación identitaria.

Desde un punto de vista estético, este sistema en formación da cuenta de la búsqueda de un lenguaje propio y diferenciado y del esfuerzo por recuperar una concepción - real o imaginada - de la expresión artística tradicional, lo que provoca una tensión conceptual en los criterios estéticos 


\title{
Mabel García Barrera
}

ingresados al sistema ya que, en el hecho, la representación artística se encuentra mediada por la circunstancia intercultural, lo que motiva consciente o inconscientemente el desplazamiento al interior de este sistema de códigos y de criterios de ambos lados, además, de los formados en el espacio intersticial.

Desde un punto de vista comunicativo y comunicacional, este sistema en construcción legitima las producciones de arte al interior de los procedimientos de visibilización pública con que las organizaciones, líderes políticos y, también, actualmente los creadores mapuches buscan estrategias para las diversas problemáticas que los afectan en el contexto de una interculturalidad asimétrica. Sin embargo, de manera similar a otros discursos, estos textos se mueven explorando estrategias pertinentes a los objetivos de rearticulación cultural, al interior de un sistema comunicativo intercultural que se acomoda permanentemente respecto de las fuerzas que ejercen los mecanismos hegemónicos y de dominación política y cultural, como de aquellas que promueve la globalización en el marco del reconocimiento de las diferencias culturales, amparadas principalmente en la legislación de los derechos humanos y en la internacionalización de la cultura. De allí que algunas de estas prácticas resulten, a veces, ambivalentes y transitorias y, otras, fuertemente acendradas en un proyecto claro y definido.

\author{
Universidad de La Frontera* \\ Departamento de Lenguas, Literatura y Comunicación \\ Avda. Francisco Salazar 01145 \\ Casilla 54-D, Temuco (Chile) \\ mabelg@ufro.cl
}


Comunicación intercultural y arte mapuche actual

\section{BIBLIOGRAFÍA}

ALSINA, Miquel Rodrigo. "Comunicación Intercultural”, en Colección Ciencias Sociales. Barcelona: Anthropos, 1999.

ANIÑIR QUILITRARO, David. Mapurbe. Venganza a raíz. Primera edición. Producción. Talleres Gráficos "El Sindicato”. Santiago: Lord Carter (La Lle’a), 2005.

AILlAPÁn, Lorenzo. Veinte Poemas Alados de los Bosques Nativos de Chile. Región del Bío Bío: Durandal, 2005.

AZÓCAR, Alonso. Fotografía proindigenista. El discurso de Gustavo Milet sobre los mapuches. Temuco: Universidad de La Frontera, 2005.

BHABHA, Homi. El lugar de la cultura (1994). Buenos Aires: Manantial, 2002.

BÜCHLOH, Benjamín. "Introducción”, en Neo-Avantgarde and Culture Industry. Essays on European and American Art from 1955 to 1975. October Book. Cambridge, Mass, London, England: The MIT Press. 2000.

CARRASCO, Hugo. "Poesía Mapuche Actual: de la apropiación hacia la innovación cultural”, en Revista Chilena de Literatura, N 43 (1993): 76-87.

COLECTIVO WE NEWEN. Sembrando vida. Wallmapu entre imágenes y poesía. Edición Salvador Marimán y Marcela Castro. www.kolectivowenewen.tk.2007.

------- Voz de mujer. Poesía de mujeres mapuches para todos. Edición Natalia Molina Huenuqueo y Salvador Marimán. www.kolectivowenewen.tk. 2008.

COLIPÁN, Bernardo. Arco de Interrogaciones. Santiago: LOM, 2005.

DEBORD, Guy. La sociètè du spectacle (1998). Texto íntegro en castellano, 1967. De Champ Libre, traducción de Maldeojo para el "Archivo Situacionista Hispano". http://www.sindominio.net/ash/espect0.htm.

GARCÍA B., Mabel; CARRASCO M., H.; CONTRERAS H., V. Crítica Situada. El estado actual del arte y la poesía mapuche. Universidad de La Frontera. Temuco: Florencia, 2005.

GARCÍA B., Mabel. "Lenguaje, traducción y resistencia cultural en el discurso poético mapuche: "Arco de Interrogaciones" de Bernardo Colipán”, en Papeles de Trabajo $\mathrm{N}^{\circ}$ 13. Rosario: Universidad Nacional de Rosario (2005b):157-177.

"El discurso poético mapuche y su vinculación con los temas de resistencia cultural”, en Revista Chilena de Literatura Nº 68 (2006): 169-197. 
------- "Estrategias del discurso artístico mapuche como proyecto de autonomía estético-cultural”. Memorias 50 Congreso Internacional de FLACSO. Quito: (en prensa), 2007.

------- "Entre-textos: la dimensión dialógica e intercultural del discurso poético mapuche”, en Revista Chilena de Literatura, No 72 (2008).

HUIRIMILLA, Juan Pablo. Viaje al Osario. Osorno (Rahue): Edición y distribución digital, 2005.

LIENLAF, Leonel. Hierba Agua. Alepué: Propia, 2006.

MAX, Horkheimer; ADORNO, Theodor. Dialéctica del Iluminismo. (Trad. de H. A. Murena). Buenos Aires: Sudamericana, 1987.

MILlAHUEIQUE, César. Oratorio al señor de Pucatrihue. Santiago: Mosquito Comunicaciones, 2004.

RAPIMAN, Eduardo. "Apreciación del arte mapuche contemporáneo". (Texto entregado por el autor a la autora del artículo, en formato digital) Pitrufquen, 2003.

WILLIAMS, Raymond. Marxismo y Literatura. Barcelona: Península, 1980. 